\title{
Efficient Removal of Nitrogen based Industrial Pollutants by Graphene Oxide Coupled Nanotitania Composite under Visible Light Illumination
}

\author{
Ryali Somasekhar ${ }^{1}$, Paul Douglas Sanasi ${ }^{2 *}$ \\ ${ }^{1}$ Research Scholar, Department of Chemistry, Jawaharlal Nehru Technological University (JNTU), Kakinada- 533003, Andhra Pradesh, India \\ ${ }^{2}$ Department of Engineering Chemistry, Andhra University College of Engineering (A), Andhra University, Visakhapatnam- 530003, \\ Andhra Pradesh, India
}

Received: 18/09/2020

Accepted: 28/10/2020

Published: 20/03/2021

\begin{abstract}
N-based industrial pollutants like Nitrobenzene (NB) and 4-nitrophenol (4-NP) were identified as hazardous among the group of industrial chemicals by United States environmental protection agency (USPEA). Their removal from the effluents has become inevitable for the industries as a part of wastewater treatment methodology. Thus, the selected organics have been successfully removed from their aqueous solutions with nanotitania (anatase) composites incorporated with an optimum wt\% of graphene oxide (GO) through photocatalytic degradation. Kubelka-Munk function was applied for the composites in the UV-Vis diffuse reflectance spectral (UV-Vis DRS) studies and the band gap has appreciably decreased with increase in wt \% of GO in the composites. Compared to band gap in Degussa P25 (3.2 eV), the same was observed as $2.60 \mathrm{eV}$ in the nanotitania composite with $10 \% \mathrm{GO}$. These studies were correlated with Photoluminescence (PL) spectral analysis. The photodegradation and mineralization of Nitrogen containing industrial pollutants like nitrobenzene (NB) (95.7 \% COD loss) and 4- nitrophenol (4-NP) (97.2\% COD loss) were successfully achieved with the nanocomposite under visible light irradiation.
\end{abstract}

Keywords: Photocatalysis, Graphene oxide, Nanotitania, Nitrobenzene, 4-nitrophenol

\section{Introduction}

Industrial water effluents released by textile, pharmaceutical, fertilizer, leather industries contains harmful organic dyestuffs. These organic pollutants are toxic in nature due to the presence of intense colour forming moieties in their chemical structures [1]. Nitrobenzene (NB) and 4-nitrophenol (4-NP) are two such Nbased organic pollutants, which were declared as hazardous chemicals by United States Environmental Protection Agency, USEPA [2-4]. NB is used in the production of dyes, explosives, pesticides and waste waters containing more than $2 \mathrm{ppm}$ of the compound is considered as toxic by USEPA [5, 6]. High levels of exposure to NB may cause damage to liver and kidneys in human beings [7, 8]. Similarly, 4-NP is a common pollutant in aquatic systems and is widely used in the synthesis of dyes, pesticides, herbicides and pharmaceutical, which is both carcinogenic and mutagenic as declared by the USEPA $[4,9,10]$. Presence of high electron affinity - nitro group in NB and 4-NP makes the compounds restricted for the detoxification. There are methods like adsorption, photochemical reduction, ozonation, oxidation by ozone under ultraviolet irradiation, photo-assisted fenton oxidation, and supercritical oxidation for the remediation of these harmful compounds. However, they were not completely successful [11-15]. Unlike these methods, environmentally benign techniques namely, advanced oxidation processes (AOP) proved as benchmark methods for the degradation as well as their mineralization [16]. To decrease the effect of the pollutants on the aquatic life, the researchers used metal oxide semiconducting materials such as $\mathrm{TiO}_{2}, \mathrm{Fe}_{2} \mathrm{O}_{3}, \mathrm{ZnO}, \mathrm{Cu}_{2} \mathrm{O}, \mathrm{NiO}$, etc [17]. Due to its high photostability and photo efficiency, nanotitania $\left(\mathrm{TiO}_{2}\right)$ and its analogue heterogeneous forms have emerged as convincing photocatalysts for the purpose [18-20].

Among the three different crystallographic forms of titania, anatase form was proved to have superior photocatalytic activity [21-23]. Its rapid electron - hole $\left(\mathrm{e}^{-/} \mathrm{h}^{+}\right)$recombination and a wide band gap of around $3.2 \mathrm{eV}(\lambda \sim 380 \mathrm{~nm})$ limits its application only in the UV region [24]. Efforts like doping titania with a transition metal, atom or ion, treating with a suitable sensitizer of higher absorption coefficient and formation of nanocomposites with carbonaceous materials having high surface area have been made to enhance the photocatalytic applications in the visible region [25]. Titanium tetrachloride was reported as the one of the best starting material to synthesize anatase nanotitania which is applicable for the photodegradation studies in the visible region [26].

Nanocomposites synthesized by exfoliation of carbon material like graphene (GR) or graphene oxide (GO) on the

Corresponding author: Paul Douglas Sanasi,Department of Engineering Chemistry, Andhra University College of Engineering (A), Andhra University, Visakhapatnam- 530003,Andhra Pradesh, India, ORCID:0000-0002-5839-0959; E-mail: pauldouglas12@ gmail.com 
incorporating on the titania particles has emerged as an alternative pathway in the area of photocatalysis [27]. Graphene is a single atomic layer of graphite and possess exceptional electrical, mechanical and thermal properties [28]. Graphene oxide is a twodimensional carbon material synthesized from graphite (Figure 1) and contains $\mathrm{sp}^{2}$ hybridised carbon atoms that can store electrons. The presence of oxygen containing functional groups like $\mathrm{COOH}$, -OH will overcome the Vander Waal's forces and increases the inter layer spacing [29, 30]. Previously, the synthesis of $\mathrm{x} \%$ graphene oxide (GO) - nanotitania (NT) composites, characterization and their photocatalytic activity towards the degradation of some anionic and cationic organic dyes was reported [31-34].

Unlike the degradation studies of these organic dyes, this paper mainly presents the photodegradation and mineralisation of NB and 4-NP (Figure 2) in the presence of these nanocomposites. The present work also unfolds the band gap variations in the nanocomposite on introducing GO onto the surface of NT. The Photoluminescence (PL) studies will additionally support the results obtained from Kubelka - Munk function curve. A Plausible degradation mechanism and the formation of mineralization products has been proposed.

As the aqueous solutions of these organic pollutants are colourless in the visible region, dichromate method was used to study the Chemical oxygen demand (COD) in these pollutants to admit themineralization under the optimized experimental conditions. Supporting studies like effect of $\mathrm{pH}$, temperature were also performed. Superior photocatalytic degradation and mineralization was observed with the nanocomposite having 10 wt. \% GO.

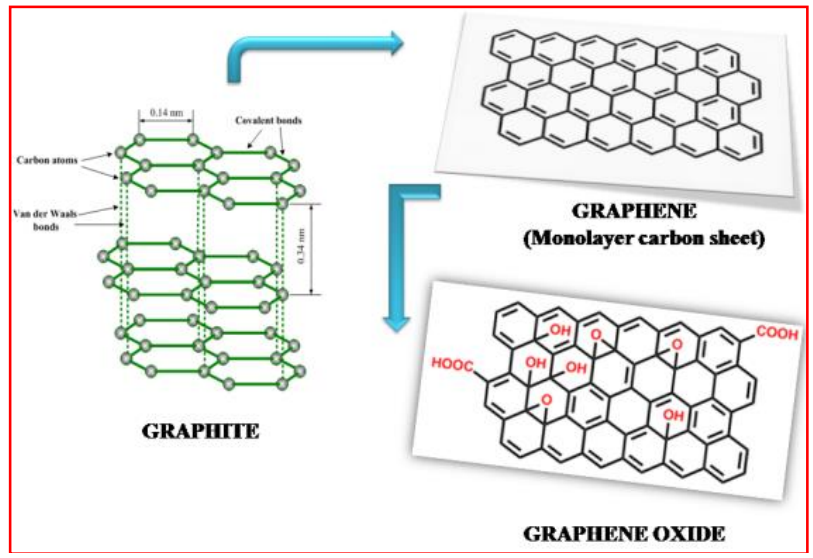

Figure 1: Conversion of graphite to graphene oxide

\section{Experimental}

\subsection{Materials}

All the chemicals were procured with AR grade quality (99\% pure) from Sigma Aldrich and Merck. Nitrobenzene with molecular formula, $\mathrm{C}_{6} \mathrm{H}_{5} \mathrm{NO}_{2}\left(\mathrm{G} . \mathrm{Mol} . \mathrm{Wt}=123.11 \mathrm{~g} \cdot \mathrm{mol}^{-1}\right)$ and 4-nitrophenol with molecular formula, $\mathrm{C}_{6} \mathrm{H}_{5} \mathrm{NO}_{3}$ (G. Mol. Wt $=139.10 \mathrm{~g} \cdot \mathrm{mol}^{-1}$ ) were chosen as the N-organic pollutants for the photocatalytic degradation study under visible light irradiation. Double distilled water (DW) was used for the experimental works.
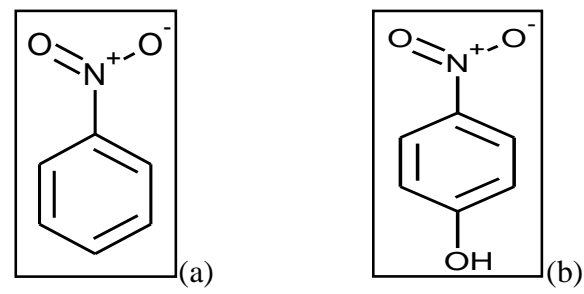

Figure 2: Chemical Structures of NB \& 4-NP

\subsection{Synthesis of $x \%$ Graphene oxide - Nanotitania composites}

Modified Hummers method was adopted to synthesise GO [32, 35]. Nanotitania composites modified with variable wt. \% of GO were synthesized using a mixture of $\mathrm{TiCl}_{4}$ and $\mathrm{H}_{2} \mathrm{O}$ in the ratio of 1:50 $\mathrm{mL}$ under ultrasonication conditions as shown in Figure 3. The finally obtained photocatalysts were designated as $1 \% \mathrm{GO}$, $2 \% \mathrm{GO}, 5 \% \mathrm{GO}$ and $10 \% \mathrm{GO}-$ nanotitania (NT) composites respectively $[31,32]$. In order to compare thephotocatalytic performance of these composites towards the degradation studies, GO free nanotitania (anatase) was also prepared separately [31].

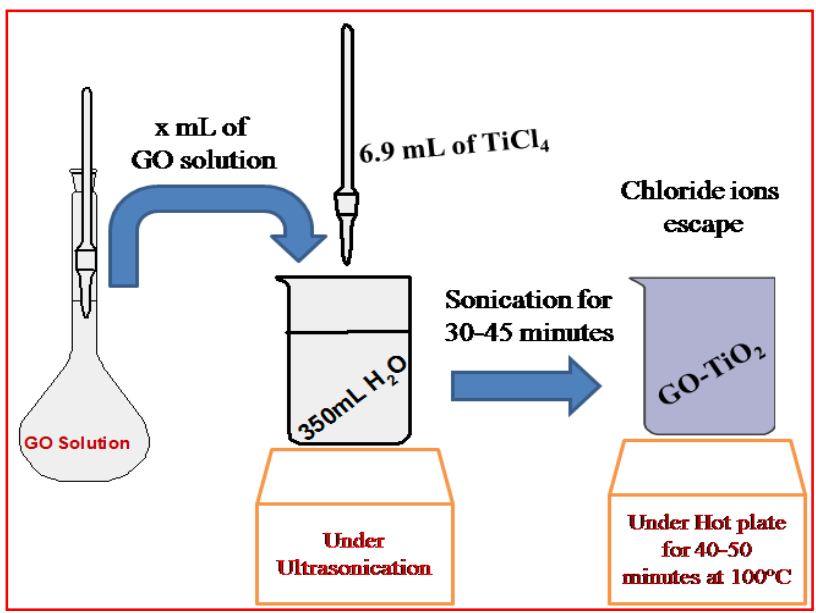

Figure 3: Facile insitu synthesis of GO - nanotitania composites

\subsection{Photocatalytic measurements}

The photocatalytic degradation tendency of the selected organic pollutants was evaluated with both the synthesized nanotitania and $\mathrm{x} \%$ GO-nanotitania composites. In $100 \mathrm{~mL}$ of the diluted aqueous solutions of the pollutants, a constant weight (10 $\mathrm{mg}$ ) of the composites was dispersed. These mixtures was kept under magnetic stirring for about 30 minutes, so that the adsorption/desorption equilibrium could be established in dark conditions. After optimizing the equilibration time, the samples were placed under 400 watt tungsten halogen lamp equipped in a wooden breakfront along with an electric supply. Then, a known volume of aliquots $(5 \mathrm{~mL})$ was extracted in regular intervals of time (15 min), centrifuged, and the translucent solutions were analyzed by using an UV-Vis spectrophotometer (UV-2550, Shimadzu, wavelength range: $180-1100 \mathrm{~nm}$ ). The percentage degradation of the pollutant was determined from Equation 1.

Photocatalytic degradation $\%=\left(\frac{\mathrm{C}_{0}-\mathrm{Ct}}{\mathrm{C}_{0}}\right) \times 100$

where $\mathrm{C}_{0}$ and $\mathrm{C}_{\mathrm{t}}$ are the initial concentration and concentration of the pollutant $(\mathrm{mg} / \mathrm{L})$ at a time interval, $\mathrm{t}(\mathrm{min})$ respectively. 


\subsection{Characterization}

The synthesized nanotitania and $\mathrm{x} \%$ GO-nanotitania composites (after calcination) were characterized. The wavelength obtained for the corresponding absorption and the band gap energy was estimated from the UV-Vis diffuse reflectance spectra, which was recorded using Single monochromator UV-2600 (optional ISR-2600 Plus, $\lambda$ up to 1400 $\mathrm{nm})$. The change in the intensity for the respective wavelength of the composites was recorded in the photoluminescence (PL) spectra at room temperature on Fluorescence spectrophotometer (F-4600, Hitachi, Japan).

\section{Results and Discussion}

The finally obtained nanotitania and its composites have been characterized using Powder X-Ray Diffraction (PXRD) including their average crystallite size, Fourier transform infrared spectroscopy (FTIR), Field emission scanning electron microscopy coupled with electron diffraction X-Ray (FESEMEDAX), High resolution transmission electron microscopy and selected area electron diffraction method (HRTEM-SAED) instrumental techniques. These results were reported earlier [3134]. In order to extend the characterization of these composites, UV-Visible diffused reflectance spectroscopy (UV-VIS DRS) and Photoluminiscence (PL) instrumental techniques were also included in the present studies. The former technique gave the band gap of the nanocomposites which was calculated using Kubelka-Munk function, and the later provided their Luminescence behavior.

\subsection{Band gap energy analysis}

The band gap energy of the bare nanotitania and $\mathrm{x} \% \mathrm{GO}$ nanotitania composites was measured by the extrapolation of the linear portion of the graph (Figure 4) between the modified Kubelka-Munk function $[\mathrm{F}(\mathrm{R}) \mathrm{h} v]^{2}$ versus photon energy $\mathrm{h} v$ in electron volts, $\mathrm{eV}$ (h is plancks constant and $v$ is the frequency of the photon energy.) [26]. The band gap was reported as $3.2 \mathrm{eV}$ for pure nanotitania [26] and around $1.9-2.6 \mathrm{eV}$ in GO [25].

In the present work, a narrow band gap was noticed in the synthesized nanotitania $(2.91 \mathrm{eV})$ compared to the commercial Degussa P25. It may be due to its concise crystallite size (14.48 $\mathrm{nm})$ [34]. Further, the band gap in the nanocomposite with $10 \mathrm{wt}$. $\%$ GO was observed to be $2.60 \mathrm{eV}$ (Table 1). These observations shows that there is shortening of band gap in the nanotitania composite on introducing the GO on its surface $[25,36]$.

The band gap in the remaining GO-NT composites was almost close to each other as observed from Figure 4. This condition might have occurred due to close agglomeration of the particles, but their band gap is less than that of the synthesized nanotitania.

\subsection{Photoluminescence $(P L)$ spectral analysis}

The PL studies were performed to identify the efficiency of the nanotitania particles and the $\mathrm{x} \% \mathrm{GO}$-nanotitania composites towards the charge carrier trapping, immigration and transfer, and to analyze the recombination rate of photogenerated electron hole pairs [37]. As depicted in Figure 5, the intensity of the synthesized nanotitania particles was observed at $425 \mathrm{~nm}$. With a gradual increase in the wt \% of GO in the nanotitania composites, the intensity of the peaks have decreased. The emission peaks were observed at 427, 430, 475 and $525 \mathrm{~nm}$ for the corresponding wt $\%$ of $1,2,5$ and $10 \%$ GO in the composites respectively. The intensity all these PL signals have decreased steadily compared to the bare nanotitania particles and it would lead to reduced charge recombination [38]. The very low intense peak formation for 10 $\%$ GO-NT composite shows a significant effect GO on nanotitania resulting in rapid transfer of photogenerated electrons onto the GOand separating the charges effectively in the nanotitania [39].

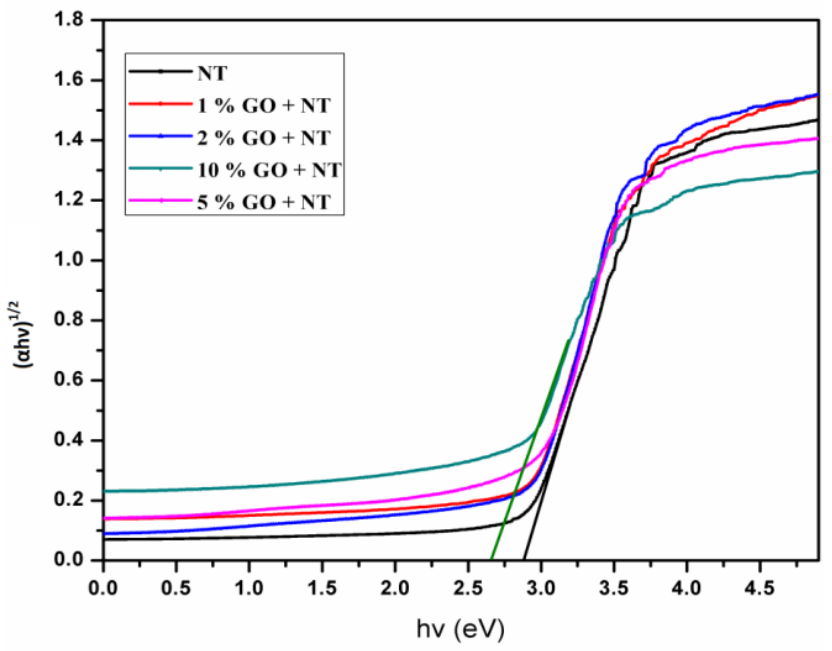

Figure 4: Band gap energy of nanotitania and $\mathrm{x} \% \mathrm{GO}$ - nanotitania composites

Table 1: Band gap energy values for the nanocomposites

\begin{tabular}{lc}
\hline \multicolumn{1}{c}{ Photocatalyst $^{[\mathrm{a}]}$} & Band gap (eV) ${ }^{[\mathrm{b}]}$ \\
\hline Degussa P25 & 3.20 \\
Nanotitania (NT) & 2.91 \\
$10 \%$ GO-NT & 2.60 \\
\hline
\end{tabular}

[a] Degussa P25 -Commercial titania, NT is synthesized in the present work. [b] Measured from Kubelka-Munk function curves.

\subsection{Photocatalytic Degradation Studies}

\subsubsection{Preparation of aqueous solution of the probe molecules} Standard solutions of NB $\left(1.5 \times 10^{-2} \mathrm{~N}\right.$, Colourless at low concentration) and 4-NP (1.15 N, at $\mathrm{pH}<6.8$-turbid to colourless) were prepared by dissolving $0.15 \mathrm{~mL}(0.19 \mathrm{~g})$ of pure NB liquid and $1.6 \mathrm{~g}$ of pure 4-NP solid in $100 \mathrm{~mL}$ of DI separately. They were kept under magnetic stirring to obtain homogenous solutions. From these solutions, $5.2 \mathrm{~mL}$ of $\mathrm{NB}$ and $0.7 \mathrm{~mL}$ of 4 NP were further dispersed in $100 \mathrm{~mL}$ of DI separately to obtain $\left[8.12 \times 10^{-5}\right] \mathrm{N}$ of $\mathrm{NB}$ and $\left[7.18 \times 10^{-5}\right] \mathrm{N}$ of $4-\mathrm{NP}(10 \mathrm{ppm})$ solutions respectively.

\subsubsection{Photocatalytic activity of the composites}

The photocatalytic performance of the synthesized nanotitania and the nanocomposites were evaluated for the degradation of NB and 4-NP aqueous solutions under visible light irradiation. In the absence of either the visible light or the photocatalyst, the tendency of degradation was found to be negligible, indicating that the degradation in the presence of photocatalysis condition could be phenomenal. $10 \mathrm{mg}$ of each photocatalyst was dispersed separately in different sets of the aqueous solutions $(100 \mathrm{~mL})$ of the probe molecules and kept in dark to establish adsorption - desorption equilibrium. The 
suspensions were then exposed to visible light irradiation and the results were presented in Figures 6 (a) \& (b).

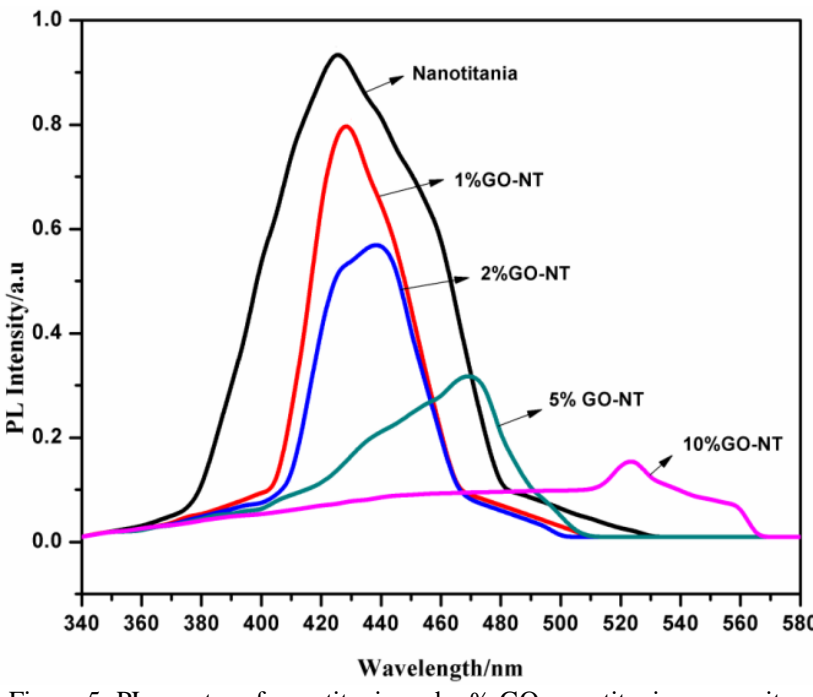

Figure 5: PL spectra of nanotitania and $\mathrm{x} \% \mathrm{GO}$-nanotitania composites

It was observed that the degradation efficiency was low with the synthesized nanotitania particles. With a gradual increase in the composition of GO in the nanocomposites, the degradation tendency has increased and reached a maximum efficiency with the $10 \%$ GO - NT for NB and 4-NP respectively. Similar degradation efficiency was observed with $15 \%$ GO - NT composite in the degradation of the pollutants. It may be due to agglomeration of the GO particles at high weight \% thereby decreasing the number of active sites on the surface of the composites. Hence, among nanocomposites with 10 and $15 \%$ $\mathrm{GO}$, the former with less wt \% of GO was considered as better photocatalyst for the degradation studies.

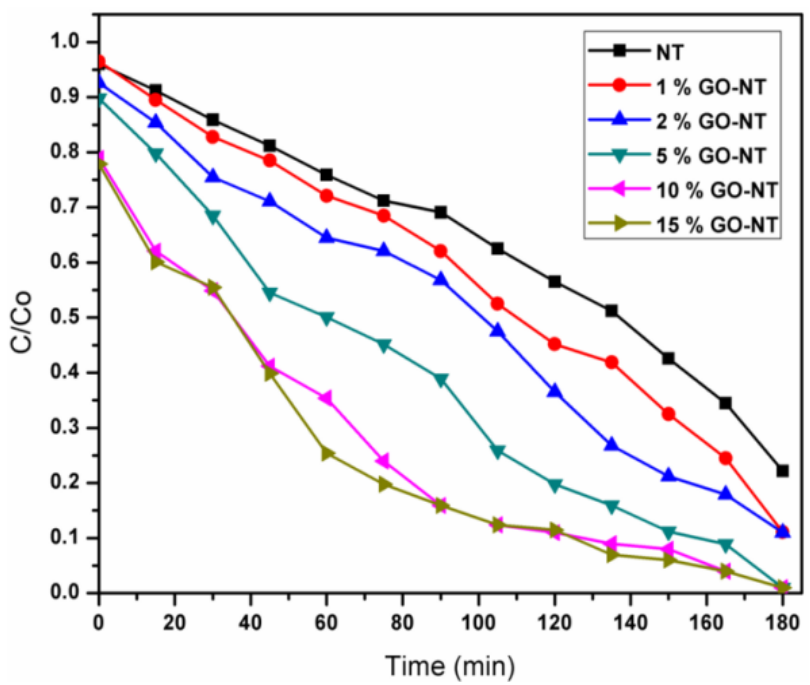

Figure 6 (a): Degradation of NB using $\mathrm{x} \%$ GO- NT composites

Figures 6 (c) \& (d) represents the study of the photocatalytic degradation of NB \& 4-NP at a wavelength range of $180 \mathrm{~nm}-360$ $\mathrm{nm}$ and $180 \mathrm{~nm}-600 \mathrm{~nm}$ respectively with $10 \%$ GO - NT composite. The aqueous solution of NB has exhibited a sharp absorption peak at $\lambda_{\max }=260 \mathrm{~nm}$. The absorbance was found to decrease with respect to time and was almost negligible in 180 minutes. Similarly, the aqueous solution of 4-NP has shown a minor absorption peak at $\lambda_{\max }=320 \mathrm{~nm}$ and an intense absorption peak at $\lambda$ max $=405 \mathrm{~nm}$. These peaks may be attributed to protonated and de-protonated forms of 4-NP respectively [4]. The absorbance corresponding to these absorption maxima was found to fall and reach a minimal in 180 minutes. These results clearly indicates an enhanced degradation efficiency of $10 \% \mathrm{GO}-\mathrm{NT}$ composite in the degradation of organic pollutants within 180 minutes (Figure 7).

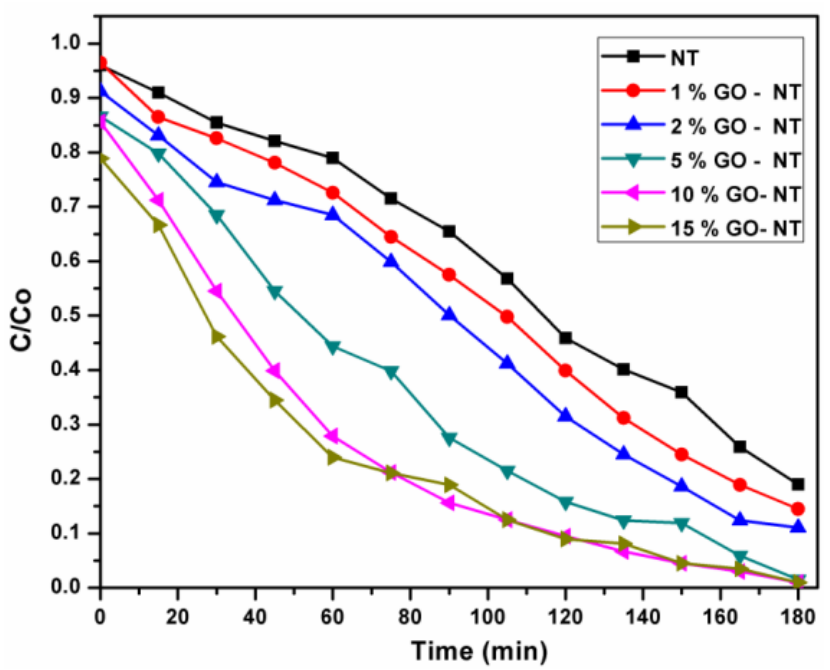

Figure 6 (b): Degradation of 4-NP using x \% GO- NT composites

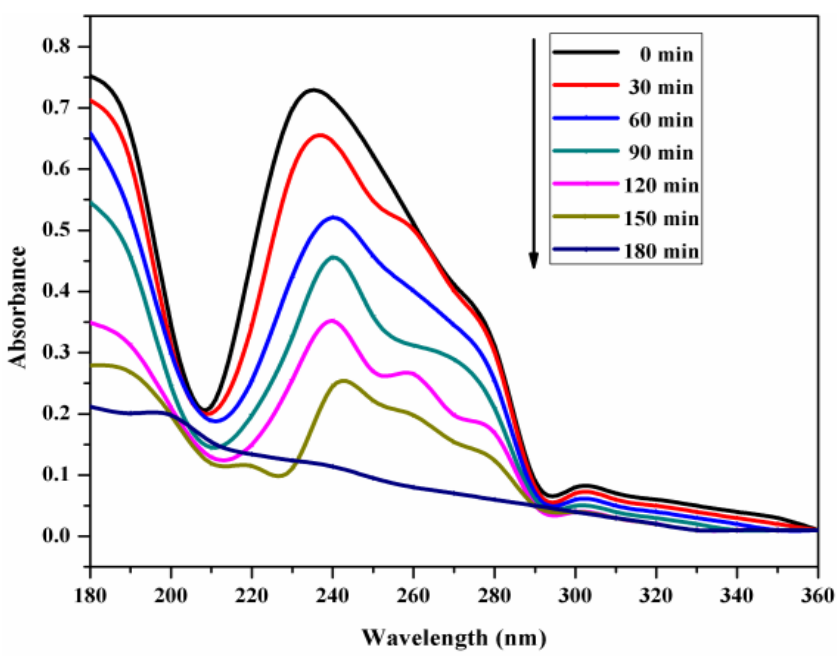

Figure 6 (c): Effect of $10 \%$ GO -NT composite on the absorbance of NB

\subsubsection{Effect of $\mathrm{pH}$}

The effect of $\mathrm{pH}$ on photocatalytic degradation of NB \& 4-NP was evaluated over the range $4.0-12.0$, into solutions with 10 ppm pollutant concentration, at an optimum nanocomposite dose (10 wt. \% GO $-\mathrm{NT}=10 \mathrm{mg} / 100 \mathrm{~mL}$ ) and for the irradiation time of 180 minutes. Perchloric acid, $\mathrm{HClO}_{4}$ and sodium hydroxide, $\mathrm{NaOH}$ solutions were used for varying the $\mathrm{pH}$ of the solutions in 
the acidic and alkaline range respectively. The degradation efficiency of organic molecules will be influenced by the surface properties of the photocatalyst and $\mathrm{pH}$ of the solution [40]. The surface properties of a photocatalyst can be understood from its zero point charge $(\mathrm{zpc})$ and for nanotitania it is 6.8 .

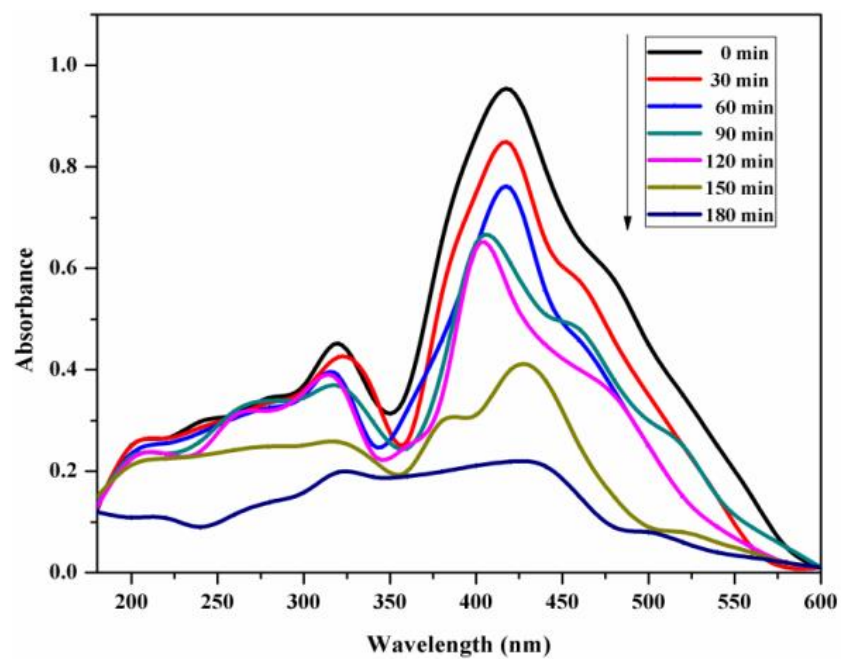

Figure 6 (d): Effect of $10 \%$ GO -NT composite on the absorbance of 4NP

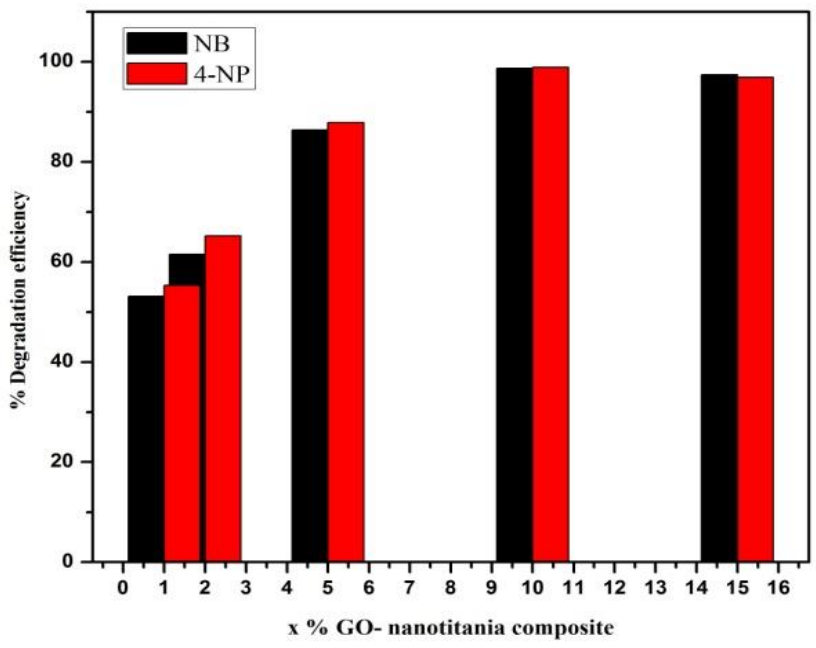

Figure 7: \% Degradation efficiency of NB \& 4-NP using x \% GO-NT composites

Its surface is positively charged in acidic range $(\mathrm{pH}<\mathrm{Pzpc})$ and negatively charged in alkaline range ( $\mathrm{pH}>\mathrm{Pzpc})$ [40]. Nonionizable compounds, like NB, will be better adsorbed on uncharged catalyst surface and their degradation rate will achieve maximum value near the zpc of the photocatalyst [41]. NB does not have neither hydroxyl group $(-\mathrm{OH})$ nor amine group $\left(-\mathrm{NH}_{2}\right)$, which can ionize at different $\mathrm{pH}$ conditions. The effect of $\mathrm{pH}$ on the photocatalytic degradation of NB was expected to be minimal was reported by few researchers [42]. However, in some studies, effective degradation tendency of NB was reported in a detectable $\mathrm{pH}$ range depending on the photocatalyst incorporated [43]. In the present work, the degradation efficiency of NB was observed to be effective in the $\mathrm{pH}$ range of $5.0-7.0$ (Figure 8 (a)). The zpc of nanotitania was 6.8 and the combined effect of GO and nanotitania might have decreased the zpc of the nanocomposite $(<6.8)$. This condition may be due to the presence of acidic functional groups present on GO making the zpc of the nanocomposite more effective for degradation in the weakly acidic range. Below and above this $\mathrm{pH}$ range, the degradation was less. The presence of deactivating nitro group in NB made the degradation tendency minimum in highly acidic/alkaline range.

In 4-NP, the hydroxyl group is a strongly activating group substituted in para - position to the nitro group and strongly activates the aromatic ring for attack of electrophilic hydroxyl radical [44]. These radicals were considered as the predominant oxidant species in the alkaline $\mathrm{pH}$ range [45]. As - $\mathrm{OH}$ group is a para-directing group and $-\mathrm{NO}_{2}$ is a meta-directing group in nature, both can influence the position of attack by hydroxyl radical [46]. In 4-NP, both groups direct the radical to ortho position, and forms nitrocatechol or nitrohydroquinone intermediates and leads to the formation of degradation products [47]. Further, in the acidic medium, the perhydroxyl radical can form hydrogen peroxide giving rise to the more reactive oxidant species, hydroxyl radicals and degrades the pollutants.

In acidic medium, 4-NP exists in protonated form $\left(\lambda_{\max }=320\right.$ $\mathrm{nm})$ and in alkaline medium, it exists in deprotonated form $\left(\lambda_{\max }=405 \mathrm{~nm}\right)$ as shown in Figure $9[4,41]$. The surface of the GO - nanotitania composite may be positively charged in the acidic medium $(\mathrm{pH}<6.8)$ and negatively charged in the alkaline medium ( $\mathrm{pH}>6.8$ ). In this view, the negatively charged form of 4NP in its highly intense deprotonated form may adsorb strongly on the surface of the nanocomposite in the acidic $\mathrm{pH}$ range. Correspondingly, its protonated form might have associated with the nanocomposite in the alkaline $\mathrm{pH}$ range. These conditions might degrade 4-NP efficiently in the $\mathrm{pH}$ range of 6.5 to 7.5 as shown in Figure 8 (b).

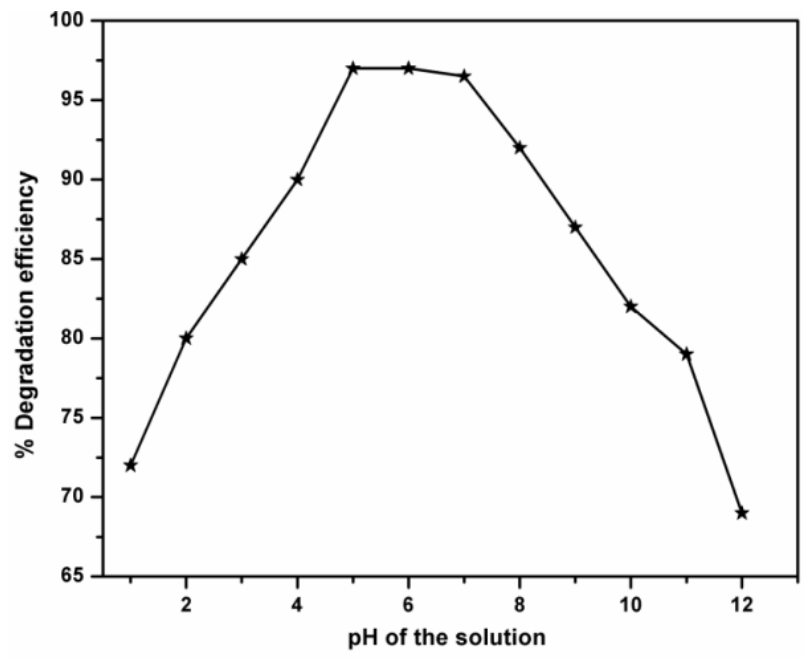

Figure 8 (a): Effect of $\mathrm{pH}$ on the degradation of NB

\subsubsection{Effect of Temperature}

The process of photocatalytic degradation is generally not highly temperature sensitive [48]. However, its impact on the degradation of organic pollutants needs to be estimated as a part of industrial applications. The effect was studied for the degradation of NB \& 4-NP in the temperature range of $20^{\circ} \mathrm{C}$ to 
$90^{\circ} \mathrm{C}$ with $10 \mathrm{mg}$ of $10 \% \mathrm{GO}-\mathrm{NT}$ composite dispersed in 10 ppm of $100 \mathrm{~mL}$ of aqueous solutions.

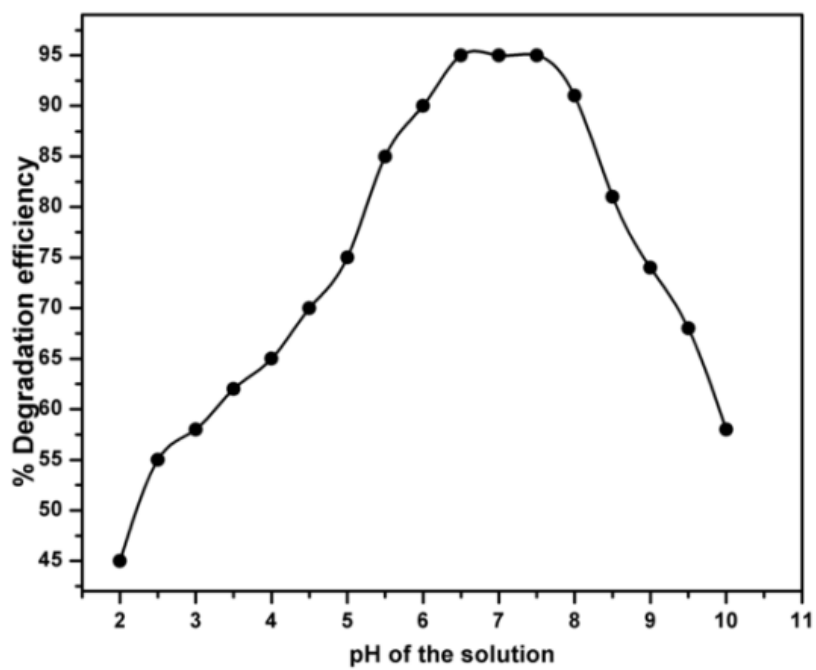

Figure 8 (b): Effect of $\mathrm{pH}$ on the degradation of 4-NP

Under the established pHconditions and the optimized irradiation time, the studies were performed and the results were displayed in Figures 10 (a) \& (b) respectively. It was observed that the \% degradation efficiency of NB \& 4-NP was maximum in the range of $40^{\circ} \mathrm{C}$ to $50^{\circ} \mathrm{C}$ and $50^{\circ} \mathrm{C}$ to $70^{\circ} \mathrm{C}$ respectively. This phenomenon of increased degradation tendency with increase in reaction temperature can be attributed to the increased collision frequency of the pollutants in the solution with increase in temperature [48]. However, at higher reaction temperatures, the solubility of dissolved oxygen will be decreased and lowers the electron withdrawal tendency from the surface of the nanocomposite [48]. This stage leads to decrease in the degradation efficiency and the same was observed in case of NB \& 4-NP respectively.<smiles>O=[N+]([O-])c1ccc(O)cc1</smiles><smiles>O=[N+]([O-])c1ccc([18OH])cc1</smiles><smiles>O=[N+]([O-])c1ccc(O)cc1</smiles>

$\mathrm{pH}>6.8$<smiles>O=[N+]([O-])c1ccc([O-])cc1</smiles>

Figure 9: Protonated and Deprotonated forms of 4-nitrophenol

\subsubsection{Evaluation of Mineralization}

In addition to the analysis of photodegradation of $\mathrm{N}$ - organic pollutants, the oxygen equivalent of organic matter in the pollutants was evaluated separately in terms of chemical oxygen demand (COD) to investigate the mineralization tendency by using dichromate $\left(\mathrm{K}_{2} \mathrm{Cr}_{2} \mathrm{O}_{7}\right)$ method [49]. For the purpose, $10 \mathrm{mg}$ of $10 \% \mathrm{GO}$ - NT composite was dispersed in $100 \mathrm{~mL}$ aqueous solutions $(10 \mathrm{ppm})$ of the organic pollutants and irradiated under visible light for 180 minutes. The experimental procedure for the determination of COD was adopted from the earlier reports [32]. Also, the COD studies were performed under the optimized $\mathrm{pH}$ and temperature conditions as established above.

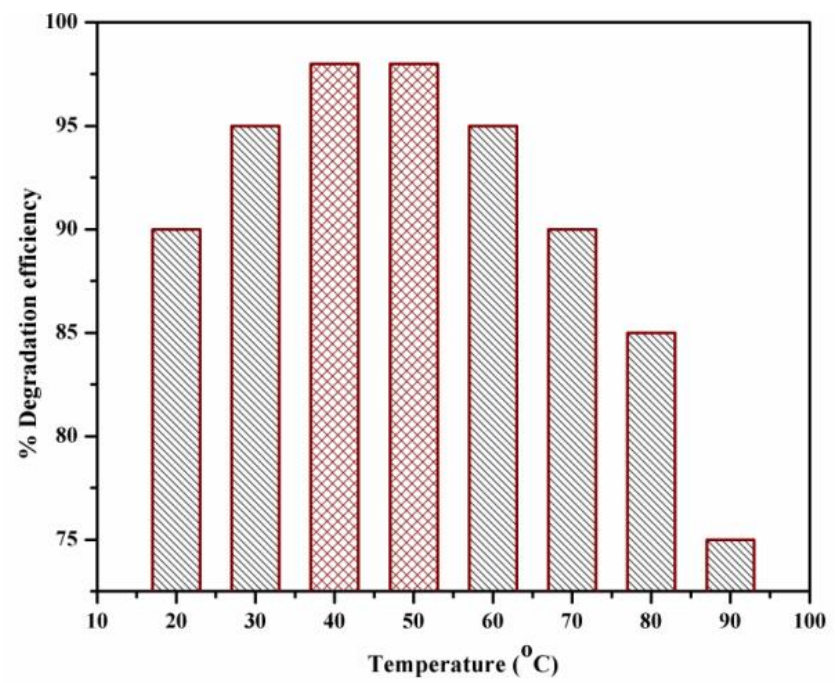

Figure 10 (a): Effect of temperature on the degradation of NB

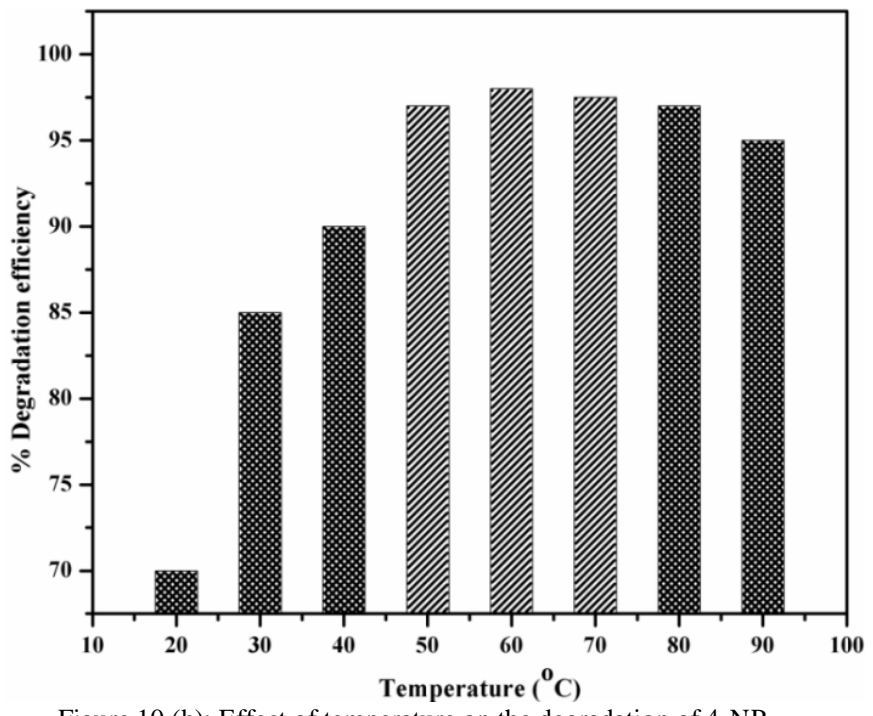

Figure 10 (b): Effect of temperature on the degradation of 4-NP

The COD content of the samples was calculated using Equation 2 and the \% loss of COD was calculated using Equation 3. Table 2 represents the results and it can be observed that there was a significant decrease in the COD of both NB \& 4-NP and the \% loss of COD was noticed as $95.7 \%$ and $97.2 \%$ respectively. These results were in close agreement with the $\%$ degradation efficiency of NB \& 4-NP (from figure 5 and $\%$ degradation was calculated using equation 1). These observations indicate that the organic compounds were efficiently degraded by the composite, along with mineralization.

$\mathrm{COD}=[\mathrm{x}-\mathrm{y}] * 0.2 * 200 \mathrm{mg} / \mathrm{L}$ 
where $\mathrm{x}$ and $\mathrm{y}$ are the volumes $(\mathrm{mL})$ of ferrous ammonium sulphate consumed for the blank (DI) and the sample under study respectively. For every, $1 \mathrm{~mL}$ difference between the titrations 0.2 $\mathrm{mg}$ of oxygen will be required by $5 \mathrm{~mL}$ sample and 200 is the numerical deduced as calculation factors.

$\%$ COD loss $=\frac{[\mathrm{COD}]_{\mathrm{O}}-[\mathrm{COD}]_{\mathrm{t}}}{[\mathrm{COD}]_{\mathrm{o}}}$

where $[\mathrm{COD}]_{\mathrm{o}}$ and $[\mathrm{COD}]_{\mathrm{t}}$ are the $\mathrm{COD}(\mathrm{mg} / \mathrm{L})$ atinitial and time $\mathrm{t}(\mathrm{min})$ respectively.

Table 2: COD studies for NB and 4-NP

Mineralization of NB \& 4-NP

$(\mathrm{pH}=5.0$ to 7.0$) ; \mathrm{pH}=5.5-6.0 \& 8.5-9.0)$

\begin{tabular}{|c|c|c|c|c|c|c|}
\hline \multirow{2}{*}{ (min) } & \multicolumn{2}{|c|}{$\mathrm{COD}(\mathrm{mg} / \mathrm{L})$} & \multicolumn{2}{|c|}{$\%$ COD loss } & \multicolumn{2}{|c|}{$\%$ Degradation } \\
\hline & NB & 4-NP & NB & 4-NP & NB & 4-NP \\
\hline 0 & 117.5 & 216.3 & - & - & - & - \\
\hline 30 & 85.3 & 145.8 & 27.3 & 32.4 & 30.4 & 36.3 \\
\hline 60 & 61.8 & 93.6 & 47.8 & 56.9 & 55.1 & 67.4 \\
\hline 90 & 39.2 & 48.1 & 66.6 & 77.7 & 79.8 & 81.7 \\
\hline 120 & 21.6 & 31.7 & 82.1 & 85.6 & 86.0 & 88.9 \\
\hline 150 & 17.3 & 16.3 & 85.4 & 92.6 & 89.8 & 94.7 \\
\hline 180 & 5.4 & 6.8 & 95.7 & 97.2 & 98.7 & 98.8 \\
\hline
\end{tabular}

\subsubsection{Plausible Mechanism for Photocatalytic Degradation}

In the phenomena of photodegradation of organic pollutants, either photocatalytic oxidation or photosensitized oxidation mechanisms were proposed [50]. Typically, nitrobenzene and 4nitrophenol are having their absorption maxima in the UV and near visible region respectively. In addition, the degradation studies were conducted under visible light active GO nanotitania composites and hence in the present work, a photocatalytic oxidation has been proposed as a possible mechanism for the degradation of the organic pollutants. On visible light incidence, the electrons present in the valence band of the nanotitania excites to the conduction band $\left(\mathrm{e}_{\mathrm{CB}}^{-}\right)$leaving a positive hole in the valence band $\left(\mathrm{h}^{+} \mathrm{vB}\right)$ [50]. In the absence of $\mathrm{GO}$, these $\mathrm{e}^{-} / \mathrm{h}^{+}$pairs combine vigorously and results in a very low photocatalytic activity [50]. The d-orbital (CB) of the nanotitania and $\pi$-orbital of the GO interact and forms a d- $\pi$ overlap which can cause synergic effect [51, 52]. In this interaction, the excited electron $\left(\mathrm{e}^{-} \mathrm{CB}\right)$ in nanotitania can be shuttled easily along the conducting network of GO surface thereby decreasing the $\mathrm{e}^{-}$ $/ \mathrm{h}^{+}$recombination in the nanocomposites. The negative electron subsequently reduces oxygen to superoxide ions and the positive hole in the valence band (VB) of nanotitania oxidizes water molecules to hydroxyl radicals. These superoxide ions and hydroxyl radicals would oxidize both NB \& 4-NP. The schematic illustrations were shown in Figure 11 and the possible photocatalytic reactions were shown in equations 4 to 8 .

$\mathrm{TiO}_{2}+\mathrm{h} v($ visible $) \rightarrow \mathrm{TiO}_{2}\left(\mathrm{e}^{-} \mathrm{CB}\right)+\mathrm{TiO}_{2}\left(\mathrm{~h}^{+}{ }_{\mathrm{vB}}\right)$
$\mathrm{TiO}_{2}\left(\mathrm{e}^{-} \mathrm{cB}\right)+\mathrm{GO} \rightarrow \mathrm{GO}\left(\mathrm{e}^{-}\right)+\mathrm{O}_{2} \rightarrow \mathrm{O}_{2}{ }^{-}$

$\mathrm{TiO}_{2}\left(\mathrm{~h}^{+} \mathrm{vB}\right)+\mathrm{H}_{2} \mathrm{O} \rightarrow \mathrm{TiO}_{2}+\mathrm{H}^{+}+\mathrm{OH}^{\cdot}$

$\mathrm{TiO}_{2}\left(\mathrm{~h}^{+} \mathrm{vB}\right)+\mathrm{OH}^{-} \rightarrow \mathrm{TiO}_{2}+\mathrm{OH}^{\cdot}$

$\mathrm{O}_{2}{ }^{-} / \mathrm{OH}^{*}+\mathrm{NB} / 4-\mathrm{NP} \rightarrow$ intermediates $\rightarrow \mathrm{CO}_{2}+\mathrm{H}_{2} \mathrm{O}+\mathrm{HNO}_{3}$ (mineralization products)

\subsubsection{Evaluation of products on mineralization}

The dissociation pathway for the degradation of nitrobenzene was pictured in Figure 12 (a). On reacting with the hydroxyl radical (obtained from the GO-NT composite under light illumination), a transition state could be formed in which the electrophilic hydroxyl radical substitutes on the aromatic ring. Immediately, it may stabilize itself through formation of isomeric nitrophenols as disproportionate products. These products break into the mineralization products of nitrobenzene like $\mathrm{CO}_{2}, \mathrm{H}_{2} \mathrm{O}$, $\mathrm{HNO}_{3}$ [53]. The mechanistic formation of degradation products of 4 - nitrophenol was portrayed in Figure 12 (b). On visible light illumination, the hydroxyl radical substitutes the deactivating nitro group and forms an intermediate oxy radical. It undergoes rearrangement to forms para - hydroxy phenol and hydroquinone as intermediate products which finally dissociates into mineralization products of the pollutant like $\mathrm{CO}_{2}, \mathrm{H}_{2} \mathrm{O}, \mathrm{HNO}_{3}$ or $\mathrm{HNO}_{2}[54]$

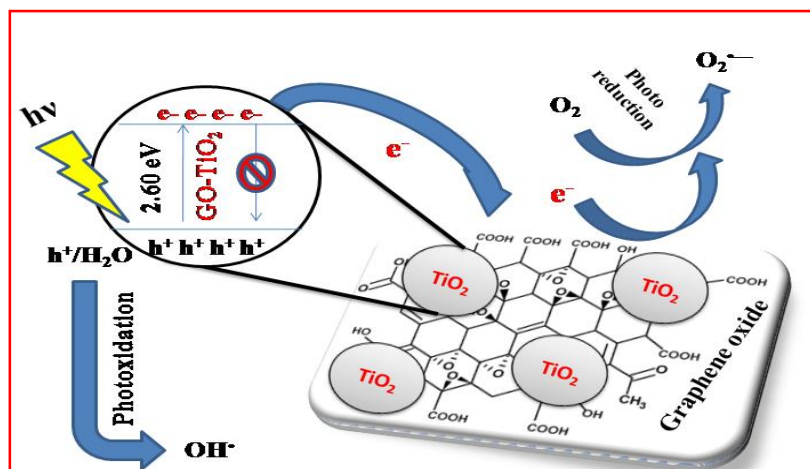

$\mathrm{O}_{2}^{-}-$(or) $\mathrm{OH} \cdot+\mathrm{NB} \& 4-\mathrm{NP} \rightarrow$ Degraded products

Figure 11: Illustration of photocatalytic degradation of NB \& 4-NP using $10 \% \mathrm{GO}$ - NT composites under visible light irradiation

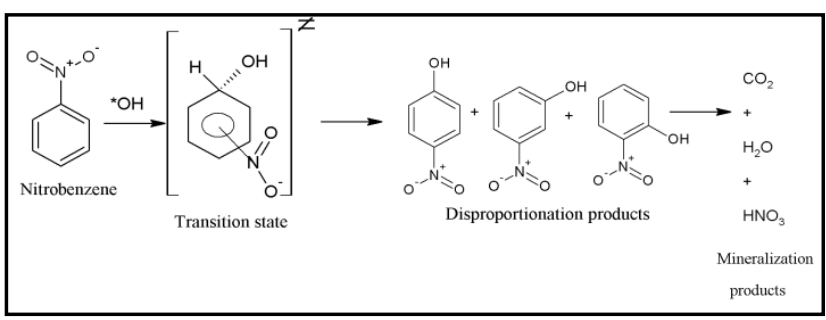

Figure 12 (a): Possible products on mineralization of NB 


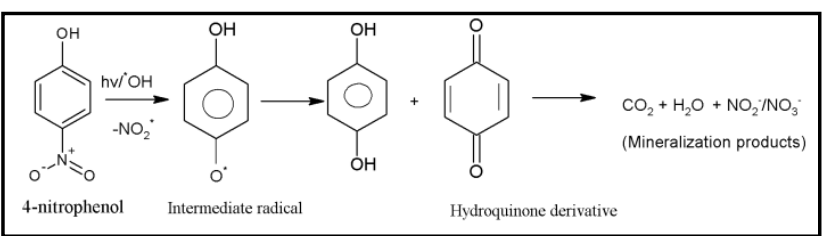

Figure 12 (b): Possible products on mineralization of 4-NP

\section{Conclusions}

The photocatalytic degradation of nitrobenzene (NB) and 4nitrophenol (4-NP) was investigated under visible light irradiation with GO-NT composites. With an optimum increase in $\%$ of GO in the composites, the degradation of the $\mathrm{N}$-organic pollutants was improved and maximum degradation was achieved with nanotitania composite having $10 \%$ wt of GO. Further, the COD studies performed under the established $\mathrm{pH}$ and temperature conditions has confirmed the photoefficiency of the composite by degrading $95.7 \%$ and $97.2 \%$ of NB and 4-NP respectively. The results of loss of COD and degradation efficiency were compared and a close nearness was observed in both the studies.

\section{Acknowledgment}

The author (RSS) thank the Management of Andhra University, Visakhaptanam for providing facilites in the Organic Chemistry Laboratory. And also Centre for Advanced Instrumentation, NIT-Warangal for UV-Vis DRS analysisand PL spectral analysis.

\section{Competing interests}

The authors declare that there is no conflict of interest that would prejudice the impartiality of this scientific work.

\section{Authors' contribution}

All authors of this study have a complete contribution for data collection, data analyses and manuscript writing.

\section{References}

1 Tapas KR, Nabas KM. Photocatalytic Degradation of Congo red dye on thermally activated Zinc oxide. Int $\mathbf{J}$ Sci research in Environ. Sci. $2014 ; 2$ (12): 457-469.

2 Umabala AM. Effective Visible light photo degradation of nitrobenzene using $\mathrm{BiVO}_{4}$ prepared by room temperature solid-state metathesis. Int J Sci and Res. 2015; 4 (12): 1521-1524.

3 Murthy NT, Suresh P, Umabala AM, Prasada Rao AV. Visible light activated photocatalytic degradation of nitrobenzene using $\mathrm{Cu}_{2} \mathrm{O}$. Int $\mathrm{J}$ Rec Sci Res. 2016; 7(5) : 10895-10898.

4 Murthy NT, Suresh P, Umabala AM, Prasada Rao, AV. Visible light activated photocatalytic degradation of mono-, di- and tri-nitrophenols using $\mathrm{Cu}_{2} \mathrm{O}$. Der Pharma Chemica. 2016; 8 (6): 228-236.

5 Dhananjay SB, Vishwas GP, Anthony ACMB. Photocatalytic degradation of nitrobenzene using titanium dioxide and concentrated solar radiation: chemical effects and scaleup. Water research. 2003; 37 (6):1223-1230. (doi: 10.1016/S0043-1354(02)00490-6).

6 Xiaoli W, Yu L, Yizhe WTW, Qian G, Xianyuan D. New evidence for the importance of Mn oxides contributed to nitrobenzene adsorption onto the surficial sediments in Songhua River, China. J Haz Mat. 2009; 172 (2): 755-762. (doi: 10.1016/j.jhazmat.2009.07.060).

7 Stephen AB, Guangyao S, Brian JT, Cliff TJ. Mechanisms for the Adsorption - of Substituted Nitrobenzenes by Smectite Clays. Environ Sci Technol. 2001; 35 (21):4227-4234. (doi: 10.1021/es010663w).
8 Zheng C, Zhou J, Wang J, Wang J, Qu B. Isolation and characterization of nitrobenzene degrading yeast strain from activated sludge. J Haz Mat. 2008; 160 (1): 194-199. (doi: 10.1016/j.jhazmat.2008.02.101).

9 Nevim S, Arzu H, Gulin K, Zekiye C. Photocatalytic degradation of 4nitrophenol in aqueous $\mathrm{TiO}_{2}$ suspensions: Theoretical prediction of the intermediates. J Photochem and Photobio A: Chem. 2002; 146 (3) :189-197. (doi: 10.1016/S1010-6030(01)00620-7).

10 Lixia Y, Shenglian L, Yue L, Yan X, Qing K, Qingyun C. High Efficient Photocatalytic Degradation of p-Nitrophenol on a Unique $\mathrm{Cu}_{2} \mathrm{O} / \mathrm{TiO}_{2}$ p-n Heterojunction Network Catalyst. Environ Sci Technol. 2010; 44 (19) :7641-7646. (doi: 10.1021/es101711k).

11 Fernando JB, Jose ME, Miguel AA. Nitroaromatic Hydrocarbon Ozonation in Water. 2. Combined Ozonation with Hydrogen Peroxide or UV Radiation. Ind Eng Chem Res. 1998; 37: 32-40. (doi: 10.1021/ie970426v)

12 Miguel R, Andreas K, Sandra C, Esther C, Santiago E. Influence of $\mathrm{H}_{2} \mathrm{O}_{2}$ and $\mathrm{Fe}$ (II) in the photodegradation of nitrobenzene. J photochem and photobio A: Chem. 2000; 133(1-2):123-127. (doi: 10.1016/S10106030(00)00223-9).

13 Idil AA, John LF. $\mathrm{H}_{4} \mathrm{SiW}_{12} \mathrm{O}_{40}$-catalyzed oxidation of nitrobenzene in supercritical water: kinetic and mechanistic aspects. Appl Cat B: Environ. 2002; 38(4) :283-293. (doi: 10.1016/S0926-3373(02)00059$0)$.

14 Aysegul L, Mirat DG. The effect of humic acids on nitrobenzene oxidation by ozonation and $\mathrm{O}_{3} / \mathrm{UV}$ process. Water Res. 2003; 37 (8) :1879-1889. (doi: 10.1016/S0043-1354(02)00583-3).

15 Yang Mu HQY, Jia-Chuan Z, Shu-Juan Z, Guo-Ping S. Reductive degradation of nitrobenzene in aqueous solution by zero-valent iron. Chemosphere. 2004; $54 \quad$ (7): 789-794. (doi: 10.1016/j.chemosphere.2003.10.023).

16 Movahedi, M, Mahjoub AR, Janitabar-Darzi S. Photodegradation of Congo red in aqueous solution on $\mathrm{ZnO}$ as an alternative catalyst to $\mathrm{TiO}_{2}$. J Iranian Chem Soc. 2009; 6(6) :570-577. (doi: 10.1007/BF03246536).

17 Azita N, Ali F, Arezu N. Photocatalytic degradation of methyl orange and Congo red using C, N, S - tridoped $\mathrm{SnO}_{2}$ nanoparticles. J Phy and Theo Chem. 2014; 10(4): 225-230.

18 Howe RF. Recent developments in photocatalysis. Dev Chem Eng Mineral Process. 1998; 6(1): 55-84.

19 Bing G, Hangyan S, Kangying S, Yaowu Z, Wensheng N. The study of the relationship between pore structure and photocatalysis of mesoporous $\mathrm{TiO}_{2}$. J Chem Sci. 2009; 121: 317. (doi: 10.1007/S12039009-0036-5).

20 Ayad FA, Mohammed BA. Adsorption and Photocatalytic degradation of crystal violet dye in the presence of different metals doping on $\mathrm{TiO}_{2}$. J Appl Chem. 2013; 2(2): 291-303.

21 Detlef WB. Ultra small Metal Oxide Particles: Preparation, Photophysical Characterization, and Photocatalytic Properties. Israel J Chem. 1993; 33(1): 115-136. (doi: 10.1002/ijch.199300017).

22 Mohsen P, Mahboubeh T, Mohammad RG. Effective photocatalytic degradation of an azo dye over nanosized $\mathrm{Ag} / \mathrm{AgBr}$-modified $\mathrm{TiO}_{2}$ loaded on zeolite. Chemical papers. 2011; 65: 280-288. (doi: 10.2478/s11696-011-0013-6).

23 Sammy WV, Tom T, Steven VP, Johan AM, Silvia L. Cost effectiveness analysis to assess commercial $\mathrm{TiO}_{2}$ photocatalysts for acetaldehyde degradation in air. Chemical papers. 2014 (doi: 10.2478/s1 1696-014-2557-3).

24 Babji P, Nageswara Rao I, Das SK. Synthesis, Characterization and Antitumor activity of $\mathrm{Fe}_{2} \mathrm{O}_{3}-\mathrm{Ag}_{2} \mathrm{O}-\mathrm{TiO}_{2}$ Nanocomposite on MCF-7 human breast cancer cells. J Appl Chem. 2015; 4(2): 550-556.

25 Thuy-Duong NP, Viet HP, Eun WS, Hai-Dinh P, Sunwook K, Jin SC, Eui JK, Seung HH. The role of graphene oxide content on the adsorption-enhanced photocatalysis of titanium dioxide/graphene oxide composites. Chem Engg J. 2011; 170 :226-232. (doi: 10.1016/j.cej.2011.03.060).

26 Maurizio A, Vincenzo A, Agatino DP, Elisa GL, Vittoric L, Giuseppe $\mathrm{M}$, Leonardo P. Preparation and photoactivity of nanostructured $\mathrm{TiO}_{2}$ 
particles obtained by hydrolysis of $\mathrm{TiCl}_{4}$. Coll Surf A Physciochem Eng Aspects. 2005; 265: 23-31. (doi: 10.1016/j.colsurfa.2004.11.048).

27 Wan KJ, Hyun JK. Titanium dioxide-graphene oxide composites with different ratios supported by Pyrex tube for photocatalysis of toxic aromatic vapors. Powder technology. 2013; 250: 115-121. (doi: 10.1016/j.powtec.2013.10.017).

28 Raji A, Thomas Nesakumar JIE, Suguna P, Dhanapalan K, Yong RL. Effective photocatalytic degradation of anthropogenic dyes using graphene oxide grafting titanium dioxide nanoparticles under UV-light irradiation. J Photochem and Photobio A: Chem. 2017; 333: 92-104. (doi: 10.1016/j.jphotochem.2016.10.021).

29 Sasha S, Dmitriy AD, Richard DP, Kevin AK, Alfred K, Yuanyuan J, Yue W, SonBinh TN, Rodney SR. Synthesis of graphene-based nanosheets via chemical reduction of exfoliated graphite oxide' Carbon. 2007; 45(7): 1558-1565. (doi: 10.1016/j.carbon.2007.02.034).

30 Thanh XN, Mo TN, Hung VN, Hung VH. Synthesis of Graphene Titanium dioxide composites as photocatalytic materials for degradation of Moderacid Black. Asian J Chem. 2016; 28 (6) :12971303. . (doi: 10.14233/ajchem.2016.19660).

31 Douglas SP, Sekhar RS. Facile synthesis of graphene oxide nanotitania composites and evaluation for visible light assisted photocatalytic degradation of Rhodamine B. Asian J Chem. 2018; 30 (6): 1284-1290. (doi: 10.14233/ajchem2018.21219).

32 Douglas SP, Sekhar RS. Graphene oxide-nanotitania composite for efficient photocatalytic degradation of Indigo carmine. J Chin Chem Soc. 2018; 65(12): 1423-1431. (DOI: 10.1002/jccs.201800154).

33 Douglas SP, Sekhar RS. Effect of graphene oxide on nanotitania particles in visible light induced photocatalytic degradation of Congo red .J Appl Chem. 2017; 6: 1200 .

34 Sekhar RS, Raju MN. Nanotitania composite assembled with graphene oxide for photocatalytic degradation of Eosin yellow under visible light. Nanochem Res. 2018; 3 (2): 160-169. (DOI: 10.22036/ncr.2018.02.005).

35 Devi R, Prabhavathi G, Yamuna R, Ramakrishnan S, Nikhil Kothurkar $\mathrm{K}$. Synthesis, characterization and photoluminescence properties of graphene oxide functionalized with azo molecules. J Chem Sci. 2014; 126: 75-83. (doi: 10.1007/s12039-013-0536-1).

36 Donglin Z, Guodong S, Changlun C, Xiangke W. Enhanced photocatalytic degradation of methylene blue under visible irradiation on graphene@ $\mathrm{TiO}_{2}$ dyade structure. Appl Cat B: Environ. 2012; 111: 303-308. (doi: 10.1016/j.apcatb.2011.10.012).

37 Yamashita H, Ichihashi Y, Harada M, Stewart G, Gox MA, Anpo M. Photocatalytic degradation of 1-octanol on anchored titanium dioxide and on $\mathrm{TiO}_{2}$ powder catalysts. J Catal. 1995; 158: 97-101. (doi: 10.1006/jcat.1996.0010).

38 Quanjun X, Jiaguo Y, Mietek J. Enhanced photocatalytic $\mathrm{H}_{2}$ production activity of graphene-modified titania nanosheets. Nanoscale. 2011; 3: 3670-3678. (doi: 10.1039/C1NR10610D).

39 Ping C, Zhi Y, Hong W, Wei C, Mingxia C, Wenfeng S, Guifu D. $\mathrm{TiO}_{2}$-graphene nanocomposites for photocatalytic hydrogen production from splitting water. Int $\mathrm{J}$ hyd ene. 2012; 37: 2224. (doi: 10.1016/j.ijhydene.2011.11.004).

40 Konstantinou IK, Albanis TA. $\mathrm{TiO}_{2}$ - assisted photocatalytic degradation of azo dyes in aquesous solution: kinetic and mechanistic investigations A review. Appl Catal B:Eviron. 2004; 49: 1-14. (doi: 10.1016/j.apcatb.2003.11.010).

41 Dhananjay SB, Sanjay PK, Sudhir BS, Vishwas GP. Photocatalytic and photochemical degradation of nitrobenzene using artificial ultraviolet light. Chem. Eng. J. 2004; 102: 283-290. (doi: 10.1016/j.cej.2004.05.009)

42 Dhananjay SB, Vishwas GP, Anthony ACMB. Photocatalytic degradation for environmental applications - a review. J Chem Technol Biotechnol. 2001; 77: 102-116. (doi: 10.1002/jctb.532)

43 Rajesh JT, Ramachandra GK, Raksh VJ. Photocatalytic Degradation of Aqueous Nitrobenzene by Nanocrystalline $\mathrm{TiO}_{2}$. Ind Eng Chem Res. 2006; 45: 922-927. (doi: 10.1021/ie051060m)
44 Priya MH, Giridhar M. Photocatalytic degradation of nitrobenzenes with combustion synthesized nano- $\mathrm{TiO}_{2}$. J Photochem. and Photobio. A: Chem. 2006; 178: 1-7. (doi:10.1016/j.jphotochem.2005.06.012).

45 Tunesi S, Anderson M. Influence of chemisorption on the photodecomposition of salicylic acid and related compounds using suspended titania ceramic membranes. J Phys Chem. 1991; 95: 33993405. (doi: 10.1021/j100161a078).

46 Wang KH, Hsieh YH, Chou MY, Chang CY. Photocatalytic degradation of 2-chloro and 2-nitrophenol by titanium dioxide suspensions in aqueous solution. Appl Catal. B: Environ. 1999; 21: 18. (doi: 10.1016/S0926-3373(98)00116-7).

47 Dieckmann MS, Gray KA. A comparision of the degradation of 4nitrophenol via direct and sensitized photocatalysis in $\mathrm{TiO}_{2}$ slurries. Water Res. 1996; 30: 1169-1183. (doi: 10.1016/0043-1354(95)002405).

48 Dingwang C, Ajay KR. Photodegradation kinetics of 4-nitrophenol in $\mathrm{TiO}_{2}$ suspension' Water Res. 1998; 32(11) :3223-3234. (doi: 10.1016/S0043-1354(98)00118-3)

49 Mendham J, Denney R C, Barnes J D, Thomas M, Sivasankar B (2009) Vogel's Quantitative Chemical analysis,Pearson (ed.), New Delhi, India $6^{\text {th }}$ Edition $10: 370-371$.

50 Prasada Rao AV, Umabala AM, Suresh P. Non-TiO 2 based photocatalysts for remediation of hazardous organic pollutants under green technology -present status: A review. J Appl Chem. 2015; 4: 1145-1172.

51 Jingfei L, Mengjing C, Wenhua H. Synthesis, Characterization and photocatalytic activity of new photocatalyst $\mathrm{ZnBiSbO}_{4}$ under visible light irradiation. Int $\mathrm{J}$ Mol Sci. 2014; 15: 9459-9480. (doi: 10.3390/ijms15069459).

52 Hung JH, Shi YZ, Ping YL, Shien DT, Hai PC. Confined migration of induced hot electrons in $\mathrm{Ag} /$ graphene/ $\mathrm{TiO}_{2}$ composite nanorods for plasmonic photocatalytic reaction. Opt. Exp. 2016; 24:15603-15608. (doi: 10.1364/OE.24.015603).

53 Xiantao S, Lihua Z, Nan W, Ting ZHT. Selective photocatalytic degradation of nitrobenzene facilitated by molecular imprinting with a transition state analog. Catal today. 2014; 225 :164-170. (doi: 10.1016/j.cattod.2013.07.011).

54 Di PA, Augugliaro V, Palmisano L, Pantaleo G, Savinov E. Heterogeneous photocatalytic degradation of nitrophenols' J. Photochem and Photobio. A: Chem. 2003; 155(1-3) :207-214. (doi:10.1016/S1010-6030(02)00390-8). 